\title{
Journal of Bacteriology and

\section{Amount of Haemophilus influenzae Genomic DNA in Middle Ear Fluids of Pediatric Acute Otitis Media}

\author{
Atsuko Masuno ${ }^{1 \#}$, Muneki Hotomi ${ }^{1 * \#}$, Akihisa Togawa ${ }^{1}$, Rinya Sugita $^{2}$ and Noboru Yamanaka ${ }^{1}$ \\ ${ }^{1}$ Department of Otorhinolaryngology-Head and Neck Surgery, Wakayama Medical University, Wakayama, Japan \\ ${ }^{2}$ Sugita ENT Clinic, Chiba, Japan \\ \#Muneki Hotomi and Atsuko Masuno contribute equally in this study.
}

"Corresponding author: Muneki Hotomi, Department of Otolaryngology-Head and Neck Surgery, Wakayama Medical University, 811-1, Kimiidera, Wakayama-shi, Wakayama, 641-8510, Japan, Tel: +81-73-441-0651, Fax: +81-73-446-3846; E-mail: mhotomi@wakayama-med.ac.jp

Received date: January 04, 2016; Accepted date: January 25, 2016; Published date: January 29, 2016

Copyright: (c) 2016 Masuno A, et al. This is an open-access article distributed under the terms of the Creative Commons Attribution License, which permits unrestricted use, distribution, and reproduction in any medium, provided the original author and source are credited.

\begin{abstract}
Background: Nontypeable Haemophilus influenzae (NTHi) is a leading causative pathogen responsible for acute otitis media (AOM).

Objective: In this study, we applied real-time PCR to quantify the amount of genomic NTHi DNA in MEEs and to evaluate the influence of the amount of bacteria in MEEs on the clinical outcome of AOM.

Methods: Thirty-two children with severe AOM were evaluated for the quantification of the amount of NTHi genomic DNA in middle ear effusions (MEEs) by real-time PCR.

Results: The improvement of tympanic membrane abnormalities at the second visits was significantly worse in cases with MEEs containing dense NTHi genomic DNA rather than in cases with MEEs containing sparse NTHi genomic DNA. The amount of NTHi DNA genome in MEEs were significantly higher in cases of which improvement ratio of tympanic membrane abnormalities at the second visit was less than $50 \%$ than in cases of which improvement ratio of tympanic membrane abnormalities above $50 \%$.
\end{abstract}

Discussion: It is important to predict the clinical futures of AOM for appropriate treatments. The quantity of infected pathogens will be an important factor for poor clinical outcomes of AOM.

Conclusion: The current findings suggest that severity of tympanic membrane abnormalities evaluated scoring system proposed by Japanese AOM guideline reflect the amount of NTHi in MEEs and that predict the poor improvement of AOM.

Keywords: Haemophilus influenzae infection; Acute otitis media; Middle ear fluid; Real-time PCR

\section{Abbreviations:}

PCR: Polymerase Chain Reaction; NTHi: Nontypeable Haemophilus influenzae, AOM: Acute Otitis Media; DNA: Deoxyribonucleic Acid; MEE: Middle Ear Effusions; PBS: Phosphate Buffered Saline; Ct: Cycle Threshold

\section{Introduction}

Acute otitis media (AOM) is one of the common bacterial infections in childhood [1], with nontypeable Haemophilus influenzae (NTHi) being a leading causative pathogen responsible for AOM [2-4]. The causative pathogens frequently colonize the nasopharynx and infect to the middle ear via the Eustachian tubes [5].

Although isolation of bacteria from MEEs has long been the gold standard for the etiologic diagnosis of the causative pathogens for AOM, only approximately $50 \%-60 \%$ of MEE samples from pediatric $\mathrm{AOM}$ are culture-positive for any of the major causative pathogens
[2-4,6]. In 1993, we reported the first application of the polymerase chain reaction (PCR) to identifying NTHi in culture-negative MEEs from children with otitis media with effusion (OME) [7].

Gene amplification methods have increasingly been used in the etiological diagnosis of microbial infections in an effort to evaluate precise prevalence of pathogens present in middle ear effusions (MEEs) [8-14]. Although NTHi is a fastidious bacterium that is difficult to identify by conventional culture methods, gene amplification methods can reveal the existence of this bacteria in MEEs [7,15,16].

The recent advantages in molecular identification further emphasize the importance that bacterial density plays in the pathogenesis of infectious diseases [17-21]. Previously, we revealed that quantitative real-time PCR can be used to detect the increase in both the density of nasopharyngeal pneumococci and the ratio at which this pathogen can be detected during the onset of pediatric AOM [22].

In this study, we applied real-time PCR to quantify the amount of genomic NTHi DNA in MEEs and to evaluate the influence of the amount of bacteria in MEEs on the clinical outcome of AOM. The improvement of tympanic membrane abnormalities at second visits 
was significantly worse in cases with MEEs containing large amount of genomic NTHi DNA than it was in cases with MEEs containing small amount of genomic NTHi DNA. The amount of pathogens will be an important factor in predicting poor clinical outcomes of AOM.

\section{Materials and Methods}

\section{Patients}

Thirty-two children with severe AOM were evaluated in this study. They ranged in age from 6 months old to 8 years old (median 21.5 months old) and included 16 boys and 16 girls. All of the children had been patients at the Sugita ENT Clinics between July 2006 and June 2011. In addition, they all had acute illness lasting $<48$ hours, had no spontaneous ear drum perforations, and had not been treated with tympanostomy tubes. Myringotomy was performed at the first visit for treatment and approximately $\geq 70 \mu \mathrm{l}$ of MEE was obtained by ATOMS tap (Luminas Co. Japan). Conventional bacterial culture was performed to identify the causative pathogens in the MEEs. The amount of genomic NTHi DNA in the MEEs was assessed by real-time PCR. Eighteen (56.3\%) of the children were treated with cefditoren pivoxil at $18 \mathrm{mg} / \mathrm{kg}$ for 3 to 5 days. The remaining 14 were treated with various types of oral antibiotics for 3 to 5 days, with those antibiotics including amoxicillin clavulanate, cefcapen pivoxil, tosfloxiacin, and tebipenem pivoxil.

The diagnostic criteria and the assessment of severity for AOM were defined on the basis of the scoring system recommended by Japanese clinical practice guidelines for the diagnosis and management of AOM in children [23]. This scoring system makes use of such symptoms as fever and irritability and otalgia grades each of these parameters from 0 (none) and 2 (intermediate) to 4 (marked). The system also takes into consideration tympanic membrane changes including erythema, bulging, and otorrhea and grades each of these parameters from 0 (none) and 4 (intermediate) to 8 (marked) [23]. A total score summation of each parameter of 0,1 to 8,9 to 10 , and 11 to 12 defined normal, mild AOM, moderate $\mathrm{AOM}$ and severe $\mathrm{AOM}$, respectively.

Informed consent was obtained from the parents or guardians of the patients prior to collecting the samples. This study was approved by the ethical committee of Wakayama Medical University.

\section{Bacterial cultures}

The MEEs from the patients were examined by conventional bacterial cultures to determine the presence or absence of NTHi. Briefly, a small amount (approximately 10 to $20 \mu \mathrm{l}$ ) of each specimen was inoculated onto 5\% sheep blood agar plates and chocolate agar plates (Nippon Becton Dickinson Company Ltd., Tokyo, Japan) immediately after the sample was collected. The plates were then incubated for 48 hours at $37^{\circ} \mathrm{C}$ in a humidified atmosphere supplemented with $5 \% \mathrm{CO}_{2}$. $\mathrm{H}$. influenzae was identified by colony morphology, Gram-stained smear, and $\mathrm{V}$ and $\mathrm{X}$ factor requirements. $S$. pneumoniae was identified by alpha-hemolysis and colony morphology, Gram-stained smear, optochin disk sensitivity, and bile solubility.

\section{Real-time PCR}

The relative densities of protein D gene (glpQ) of NTHi were determined by real-time PCR [24]. Briefly, MEEs ( $\geq 50 \mu$ l of volume) were suspended with $\sim 1000 \mu$ of phosphate buffered saline (PBS) to reduce the viscosity ( $2 \mathrm{x}$ to $10 \mathrm{x}$ dilution). Then, the genomic DNA was extracted from the MEE specimens using the QIAamp blood mini kit.

The real-time PCR assay was carried out in a final $25 \mu$ l reaction volume that include $12.5 \mu \mathrm{l}$ TaqMan Universal Master Mix (Applied Biosystems, Foster City, Calif, USA) and $2.0 \mu$ of DNA template in 96well plates (Applied Biosystems). The primers and probe used in this study were forward primer: 5'-CTGGWGCAATGGCAGAAGTG-3', reverse primer: 5'-TCTTTACGCACGGTGTAAGGATG-3', and TaqMan probe: 5'-FAM-AATATGCCGATGGTGTTGGYCCAGGTTMGB-3'. DNA was amplified with the Applied Biosystems 7500 Realtime PCR System (Applied Biosystems). After the initial denaturation $\left(50^{\circ} \mathrm{C}\right.$ for 2 minutes and $95^{\circ} \mathrm{C}$ for 10 minutes), the reaction was followed by 40 cycles of amplification of PCR products at $95^{\circ} \mathrm{C}$ for 15 seconds and at $60^{\circ} \mathrm{C}$ for 1 minute. Amplification data were analyzed by the instrument's software (SDS, Applied Biosystems). RNase free water for negative control and DNA from respective serotypes for positive control serially diluted from $10^{1}$ to $10^{7} \mathrm{CFU} / \mathrm{ml}$ were run for the standard curve in every test. The standard curve was generated based on the cycle threshold $(\mathrm{Ct})$ values of the positive control.

The amount of protein D gene copies of NTHi in the samples were calculated based on the standard curve and adjusted based on the dilution ratio, as mentioned above. Samples with $\mathrm{Ct}$ values over 37 were defined as negative for real-time PCR. The sensitivity of the realtime PCR ranged between $0.022 \mathrm{pg} / \mathrm{ml}$ to $0.085 \mathrm{pg} / \mathrm{ml}$. Finally, we established $10^{-3} \mathrm{ng} / \mathrm{ml}$ as the cutoff value for the amount of the genomic NTHi DNA.

\section{Statistical analysis}

We performed statistical analysis using Prism 5 (GraphPad Software, Inc., La Jolla, CA, USA). The unpaired t-test was used to compare the amount of genomic NTHi DNA in the 32 children's MEEs. Correlations were analyzed by the Pearson test. A p-value of $<0.05$ was considered statistically significant.

\section{Results}

\section{Distribution of the amount of $\boldsymbol{H}$. influenzae protein $\mathrm{D}$ gene in MEEs}

The 32 MEEs were divided into 12 culture-positive and 20 culturenegative specimens. With the real-time PCR, 20 out of $32 \mathrm{MEE}$ samples contained protein $\mathrm{D}$ gene. When the amount of protein $\mathrm{D}$ gene in the MEEs from culture-positive and culture-negative specimens were determined by conventional culture methods, no differences were found between the culture-positive and culture-negative specimens (Figure 1). The 3 (25.0\%) out of $12 \mathrm{MEE}$ samples that were positive by conventional culture did not present the protein $\mathrm{D}$ gene. In contrast, the $11(55.0 \%)$ out of 20 MEE samples that were negative by conventional culture presented the protein $\mathrm{D}$ gene.

On the other hand, the 32 MEEs were also divided into 13 MEEs from children with prior antimicrobial treatment and 19 MEEs from children without prior antimicrobial treatments. No differences in the amount of protein D gene were found between the MEEs from children who had had or who had not had prior antimicrobial treatments (Figure 2). Seven (53.8\%) out of 13 MEE samples from children with prior antimicrobial treatment presented the protein $\mathrm{D}$ gene. However, only two samples were NTHi-positive by conventional bacterial culture, with one being positive and the other being negative 
via real-time PCR. In contrast, 5 out of 19 MEE samples from children without prior antimicrobial treatment did not present the protein $\mathrm{D}$ gene and 3 of them were negative by conventional bacterial culture. Eight $(28.6 \%)$ out of 14 MEEs containing genomic NTHi DNA were positive as determined by conventional bacterial culture.

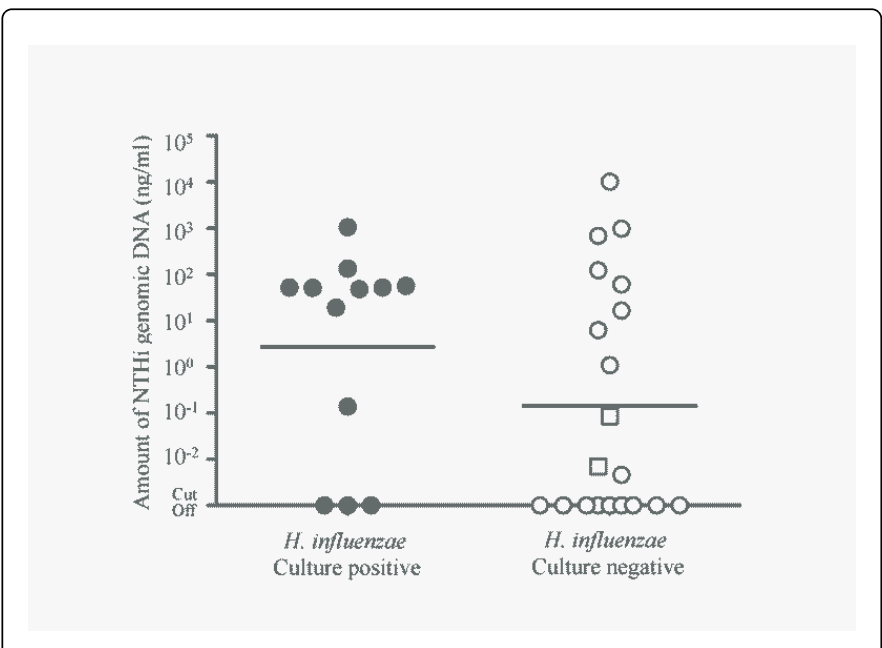

Figure 1: Distribution of the amount of NTHi protein D genes in MEEs based on the conventional bacterial cultures. Open circle: NTHi-negative by conventional culture $(n=17)$, Closed circle: NTHi-positive by conventional culture $(n=12)$, Open square: S. pneumoniae-positive, NTHi-negative by conventional culture $(n=3)$.

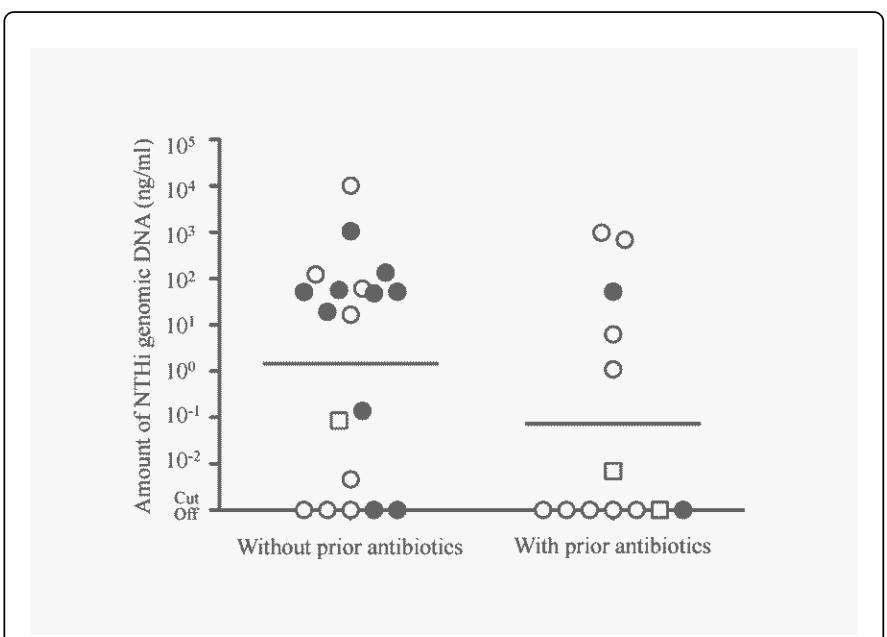

Figure 2: Distribution of the amount of NTHi protein D genes in MEEs with or without the prior antimicrobial treatments. Open circle: NTHi-negative by conventional culture, Closed circle: NTHipositive by conventional culture, Open square: $S$. pneumoniaepositive, NTHi-negative by conventional culture.

\section{Correlation between the amount of $\boldsymbol{H}$. influenzae protein $\mathrm{D}$ gene in MEEs and clinical outcomes of AOM}

At 3 to 5 days after their initial antimicrobial treatments and myringotomy, all 32 children returned for a second visit. 20 of them had NTHi DNA by real-time PCR. (Two of the 20 DNA-positive samples had pneumococci by conventional bacterial culture.) At these visits, the improvement ratios of the children's tympanic membrane abnormalities were evaluated, with the improvement ratio being determined as the ratio of a) the reduction of tympanic membrane scores before and after initial treatments to b) the initial tympanic membrane score. The improvement ratio of tympanic membrane abnormalities of $20 \mathrm{MEE}$ samples with protein $\mathrm{D}$ gene detected by realtime PCR was negatively correlated with the amount of protein $\mathrm{D}$ genes in the MEEs ( $p=0.004, r=-0.61$ ) (Figure 3). When the all 32 MEE samples were evaluated, the amount of protein D genes in MEEs were significantly higher for cases in which the improvement ratio of tympanic membrane abnormalities at the second visit was below $50 \%$ than for cases in which the improvement ratio of tympanic membrane abnormalities at the second visit was above 50\%. (In this analysis, MEEs with the cutoff value were included) (Figure 4).

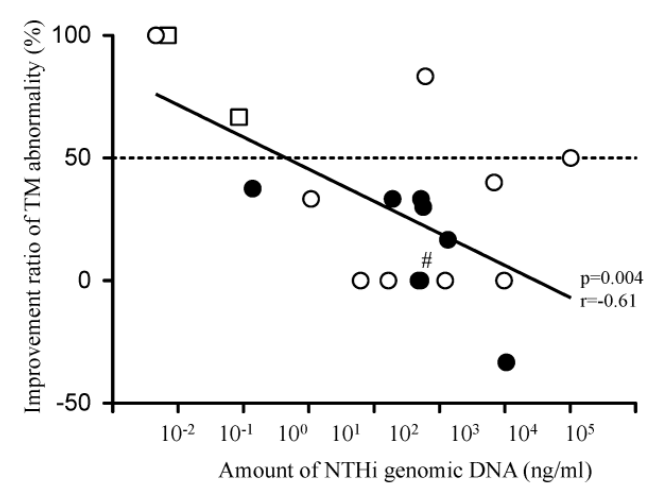

Figure 3: Correlation between the amount of NTHi protein D genes in MEEs and the improvement of tympanic membrane abnormalities at 2nd visit. Open circle: NTHi-negative by conventional culture $(\mathrm{n}=9)$, Closed circle: NTHi-positive by conventional culture $(\mathrm{n}=9, \# 3$ cases overlapped with a similar value.), Open square: S. pneumoniae-positive, NTHi-negative by conventional culture $(\mathrm{n}=2)$.

\section{Discussion}

Acute otitis media is a leading reason that oral antibiotics are prescribed during childhood $[25,26]$. The Japanese clinical practice guideline recommends evaluating the severity of AOM cases when diagnosing and managing AOM in children [23]. However, the effects of antimicrobial treatments have limitations. Cases of AOM caused by NTHi sometimes persist after initial antimicrobial treatments [27-30]. In addition, the high clinical failure rates following antibiotic treatment are related to the microbial nature of AOM [31]. On the other hand, when Stenfors et al. reported on their use of acridine orange stain to quantify the bacteria in MEEs in the early 1990s, they suggested the importance of quantitative evaluation of middle ear pathogens [32-34]. However, little effort has been focused on determining and using bacterial density as a factor for characterizing the clinical outcomes of AOM.

In this study, we found that the amount of genomic NTHi DNA was not different between culture-positive and culture-negative samples. In 
addition, this study did not find any association between previous antibiotic treatment and the amount of NTHi in the MEEs. On the other hand, previous antibiotic treatment did reduce the ability of conventional bacterial cultures to detect NTHi. In contrast to the successful application of molecular procedures to identify pathogens in MEEs, there are still considerable controversies over whether or not the bacterial DNA detected by PCR implies the existence of metabolically active bacteria.

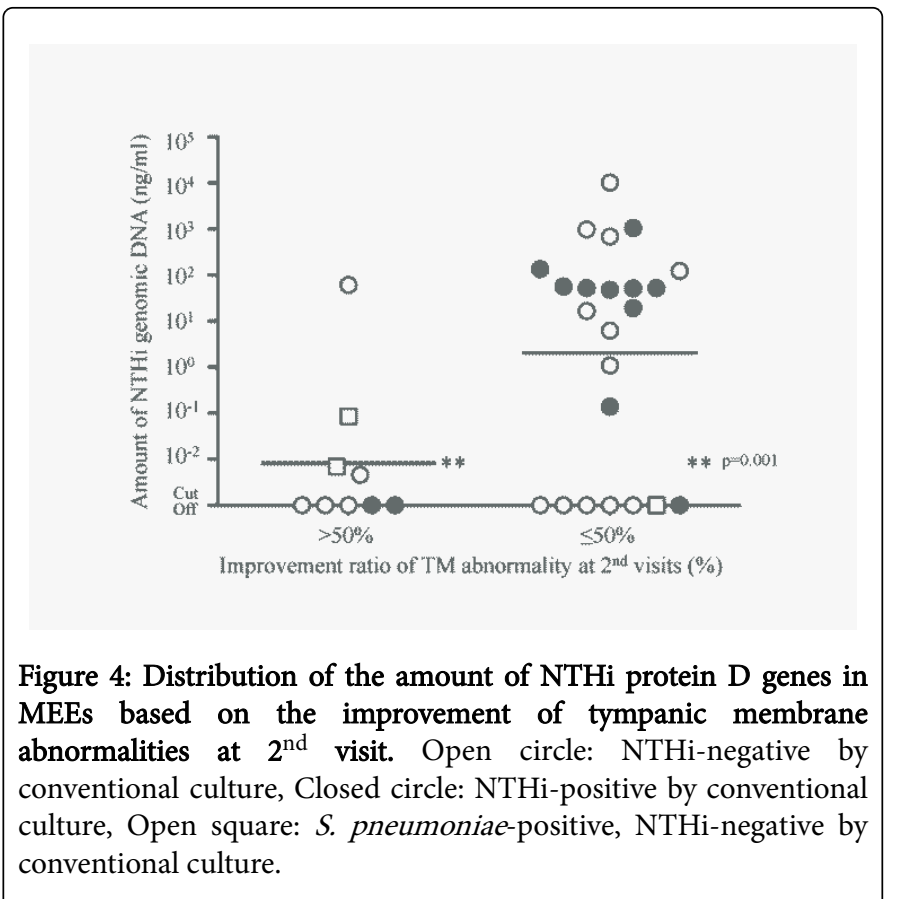

Post et al. used a chinchilla AOM model to reveal that DNA from dead bacteria does not remain detectable in MEEs [35,36]. Palmu et al. also showed that the PCR-positive rate for MEE samples decreases with time in cases of pneumococcal AOM [37]. Detection of mRNA by RT-PCR further suggested that PCR-positive but culture-negative MEEs would be caused by metabolically active NTHi [38,39]. Further, MEEs may have nuclease-inhibiting activity, and both DNA and mRNA can persist longer in MEEs. Thus, the amount of NTHi genomic DNA in MEEs will reflect the number of NTHi cells infecting the middle ear cavity while real-time PCR can detect both dead and viable NTHi.

The aim of this study was to apply real-time PCR to quantify the amount of genomic NTHi DNA in MEEs and to evaluate the influence of the amount of bacteria in MEEs on the clinical outcome of AOM. In this study, the amount of genomic NTHi DNA in MEEs was correlated with the clinical improvement of severe cases of AOM. Treatment failures and relapses of AOM are caused by several microbiological factors such as antibiotic resistance, viral-bacterial coinfection, biofilm formation, and invasion of bacteria into epithelial cells [40-42]. The presence of bacterial biofilms on mucosal membranes has been proposed as an explanation for cases having positive PCR results yet negative culture results $[43,44]$. In a biofilm, the bacteria may form a complex bacterial community attached to middle ear epithelium and covered by a protective polysaccharide matrix. These biofilms are resistant to antimicrobials and immune defense mechanisms. While they are in the biofilm phenotype, bacteria interact less with the environment and are more difficult to isolate in culture, but they may be able to survive in the middle ear for long survive.

Concerning the ability to predict the clinical outcomes of AOM, Yano et al. reported that the improvement rate of AOM based on the severity score at 1 week after the initial examination was significantly associated with the time to recovery [45]. While their findings at 1 week after the initial treatment are important to predicting the outcome of $\mathrm{AOM}$ cases, their findings were defined relatively late to predict clinical outcomes of AOM in a usual clinical setting.

The study reported here has not revealed the relationship between the amount of bacteria in MEEs and the severity of AOM. However, our unpublished study showed that the amount of bacteria in MEEs was related to the severity of AOM. Nonetheless, our current findings suggest that the severity of tympanic membrane abnormalities as evaluated using the scoring system proposed by Japanese AOM guideline will be better understanding the amount of NTHi in middle ear and that resulted in the poor improvement of AOM.

\section{References}

1. Rovers MM, Schilder AG, Zielhuis GA, Rosenfeld RM (2004) Otitis media. Lancet 363: 465-473.

2. Howie VM, Ploussard JH, Lester RL Jr (1970) Otitis media: a clinical and bacteriological correlation. Pediatrics 45: 29-35.

3. Bluestone CD, Stephenson JS, Martin LM (1992) Ten-year review of otitis media pathogens. Pediatr Infect Dis J 11: S7-11.

4. Kilpi T, Herva E, Kaijalainen T, Syrjänen R, Takala AK (2001) Bacteriology of acute otitis media in a cohort of Finnish children followed for the first two years of life. Pediatr Infect Dis J 20: 654-662.

5. Faden H, Duffy L, Wasielewski R, Wolf J, Krystofik D, et al. (1997) Relationship between nasopharyngeal colonization and the development of otitis media in children. Tonawanda/Williamsville Pediatrics. J Infect Dis 175: 1440-1445.

6. Casey JR, Pichichero ME (2004) Changes in frequency and pathogens causing acute otitis media in 1995-2003. Pediatr Infect Dis J 23: 824-828.

7. Hotomi M, Tabata T, Kakiuchi H, Kunimoto M (1993) Detection of Haemophilus influenzae in middle ear of otitis media with effusion by polymerase chain reaction. Int J Pediatr Otorhinolaryngol 27: 119-126.

8. Holder RC, Kirse DJ, Evans AK, Peters TR, Poehling KA, et al. (2012) One third of middle ear effusions from children undergoing tympanostomy tube placement had multiple bacterial pathogens. BMC Pediatr 12: 87.

9. Ueyama T, Kurono Y, Shirabe K, Takeshita M, Mogi G (1995) High incidence of Haemophilus influenzae in nasopharyngeal secretions and middle ear effusions as detected by PCR. J Clin Microbiol 33: 1835-1838.

10. Post JC, Preston RA, Aul JJ, Larkins-Pettigrew M, Rydquist-White J, et al. (1995) Molecular analysis of bacterial pathogens in otitis media with effusion. AMA 273: 1598-1604.

11. Virolainen A, Salo P, Jero J, Karma P, Eskola J, et al. (1994) Comparison of PCR assay with bacterial culture for detecting Streptococcus pneumoniae in middle ear fluid of children with acute otitis media. J Clin Microbiol 32: $2667-2670$

12. Gok U, Bulut Y, Keles E, Yalcin S, Doymaz MZ (2001) Bacteriological and PCR analysis of clinical material aspirated from otitis media with effusions. Int J Pediatr Otorhinolaryngol 60: 49-54.

13. Hendolin PH, Markkanen A, Ylikoski J, Wahlfors JJ (1997) Use of multiplex PCR for simultaneous detection of four bacterial species in middle ear effusions. J Clin Microbiol 35: 2854-2858.

14. Hendolin PH, Paulin L, Ylikoski J (2000) Clinically applicable multiplex PCR for four middle ear pathogens. J Clin Microbiol 38: 125-132.

15. Liederman EM, Post JC, Aul JJ, Sirko DA, White GJ, et al. (1998) Analysis of adult otitis media: polymerase chain reaction versus culture for bacteria and viruses. Ann Otol Rhinol Laryngol 107: 10-16. 
16. Xu Q, Kaur R, Casey JR, Adlowitz DG, Pichichero ME, et al. (2011) Identification of Streptococcus pneumoniae and Haemophilus influenzae in culture-negative middle ear fluids from children with acute otitis media by combination of multiplex PCR and multi-locus sequencing typing. Int J Pediatr Otorhinolaryngol 75: 239-244.

17. Saukkoriipi A, Palmu A, Kilpi T, Leinonen M (2002) Real-time quantitative PCR for the detection of Streptococcus pneumoniae in the middle ear fluid of children with acute otitis media. Mol Cell Probes 16: 385-390.

18. Greiner O, Day PJ, Bosshard PP, Imeri F, Altwegg M, et al. (2001) Quantitative detection of Streptococcus pneumoniae in nasopharyngeal secretions by real-time PCR. J Clin Microbiol 39: 3129-3134.

19. Greiner O, Day PJ, Altwegg M, Nadal D (2003) Quantitative detection of Moraxella catarrhalis in nasopharyngeal secretions by real-time PCR. J Clin Microbiol 41: 1386-1390.

20. Kais M, Spindler C, Kalin M, Ortqvist A, Giske CG (2006) Quantitative detection of Streptococcus pneumoniae, Haemophilus influenzae, and Moraxella catarrhalis in lower respiratory tract samples by real-time PCR. Diagn Microbiol Infect Dis 55: 169-178.

21. Wolter N, Tempia S, Cohen C, Madhi SA, Venter M, et al. (2014) High nasopharyngeal pneumococcal density, increased by viral coinfection, is associated with invasive pneumococcal pneumonia. J Infect Dis 210: 1649-1657.

22. Ogami M, Hotomi M, Togawa A, Yamanaka N (2010) A comparison of conventional and molecular microbiology in detecting differences in pneumococcal colonization in healthy children and children with upper respiratory illness. Eur J Pediatr 169: 1221-1225.

23. Kitamura K, Iino Y, Kamide Y, Kudo F, Nakayama T, et al. (2015) Clinical practice guidelines for the diagnosis and management of acute otitis media (AOM) in children in Japan - 2013 update. Auris Nasus Larynx 42: 99-106.

24. Wang X, Mair R, Hatcher C, Theodore MJ, Edmond K, et al. (2011) Detection of bacterial pathogens in Mongolia meningitis surveillance with a new real-time PCR assay to detect Haemophilus influenzae. Int J Med Microbiol 301: 303-309.

25. Froom J, Culpepper L, Green LA, Theodore MJ, Edmond K, et al. (2001) A cross-national study of acute otitis media: risk factors, severity, and treatment at initial visit. Report from the International Primary Care Network (IPCN) and the Ambulatory Sentinel Practice Network (ASPN). J Am Board Fam Pract 14: 406-417.

26. Coco A, Vernacchio L, Horst M, Anderson A (2010) Management of acute otitis media after publication of the 2004 AAP and AAFP clinical practice guideline. Pediatrics 125: 214-220.

27. Hotomi M, Yamanaka N, Shimada J, Ikeda Y, Faden H (2004) Factors associated with clinical outcomes in acute otitis media. Ann Otol Rhinol Laryngol 113: 846-852.

28. Hotomi M, Yamanaka N, Samukawa T, Suzumot M, Sakai A, et al. (2005) Treatment and outcome of severe and non-severe acute otitis media. Eur J Pediatr 164: 3-8.

29. Pichichero ME (2000) Recurrent and persistent otitis media. Pediatr Infect Dis J 19: 911-916.

30. Yamanaka N, Faden H (1993) Antibody response to outer membrane protein of nontypeable Haemophilus influenzae in otitis-prone children. J Pediatr 122: 212-218.
31. Dagan R, Leibovitz E, Greenberg D, Bakaletz L, Givon-Lavi N (2013) Mixed pneumococcal-nontypeable Haemophilus influenzae otitis media is a distinct clinical entity with unique epidemiologic characteristics and pneumococcal serotype distribution. J Infect Dis 208: 1152-1160.

32. Stenfors LE, Räisänen S (1988) Quantification of bacteria in middle ear effusions. Acta Otolaryngol 106: 435-440.

33. Räisänen S, Stenfors LE (1992) Bacterial quantification--a necessary complement for the comprehension of middle ear inflammations. Int J Pediatr Otorhinolaryngol 23: 117-124.

34. Stenfors LE, Räisänen S (1990) Quantitative analysis of the bacterial findings in otitis media. J Laryngol Otol 104: 749-757.

35. Post JC, Aul JJ, White GJ, Wadowsky RM, Zavoral T, et al. (1996) PCRbased detection of bacterial DNA after antimicrobial treatment is indicative of persistent, viable bacteria in the chinchilla model of otitis media. Am J Otolaryngol 17: 106-111.

36. Aul JJ, Anderson KW, Wadowsky RM, Doyle WJ, Kingsley LA, et al. (1998) Comparative evaluation of culture and PCR for the detection and determination of persistence of bacterial strains and DNAs in the Chinchilla laniger model of otitis media. Ann Otol Rhinol Laryngol 107: 508-513.

37. Palmu AA, Saukkoriipi PA, Lahdenkari MI, Kuisma LK, Makela PH, et al. (2004) Does the presence of pneumococcal DNA in middle-ear fluid indicate pneumococcal etiology in acute otitis media? J Infect Dis 189: 775-784.

38. Rayner MG, Zhang Y, Gorry MC, Chen Y, Post JC, et al. (1998) Evidence of bacterial metabolic activity in culture-negative otitis media with effusion. JAMA 279: 296-299.

39. Peizhong L, Whatmough K, Birchall JP, Wilson JA, Pearson JP (2000) Does the bacterial DNA found in middle ear effusions come from viable bacteria? Clin Otolaryngol Allied Sci 25: 570-576.

40. Hotomi M, Arai J, Billal DS, Takei S, Ikeda Y, et al. (2010) Nontypeable Haemophilus influenzae isolated from intractable acute otitis media internalized into cultured human epithelial cells. Auris Nasus Larynx 37: 137-144.

41. Moriyama S, Hotomi M, Shimada J, Billal DS, Fujihara K, et al. (2009) Formation of biofilm by Haemophilus influenzae isolated from pediatric intractable otitis media. Auris Nasus Larynx 36: 525-531.

42. Hotomi M, Fujihara K, Billal DS, Suzuki K, Nishimura T, et al. (2007) Genetic characteristics and clonal dissemination of beta-lactamasenegative ampicillin-resistant Haemophilus influenzae strains isolated from the upper respiratory tract of patients in Japan. Antimicrob Agents Chemother 51: 3969-3976.

43. Post JC (2001) Direct evidence of bacterial biofilms in otitis media. Laryngoscope 111: 2083-2094.

44. Ehrlich GD, Veeh R, Wang X, Costerton JW, Hayes JD, et al. (2002) Mucosal biofilm formation on middle-ear mucosa in the chinchilla model of otitis media. JAMA 287: 1710-1715.

45. Yano H, Yamazaki Y, Qin L, Okitsu N, Yahara K, et al. (2013) Improvement rate of acute otitis media caused by Haemophilus influenzae at 1 week is significantly associated with time to recovery. J Clin Microbiol 51: 3542-3546. 